\title{
THE ROLE OF SOME MYB GENES IN DEFENSE RESPONSE OF WHEAT AGAINST STRIPE RUST PATHOGEN
}

\author{
Al-Attala, Mohamed N. \\ Department of Plant Protection, Desert Research Center, El-Matareya, \\ Cairo, Egypt \\ E-mail: mohamed_n1181@yahoo.com
}

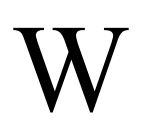

heat is one of the most important dietary crops and is a staple food in many countries. Several pathogens attack wheat in different growth stages, stripe rust is considered one of an important disease appears and causes damage by growing in the leaves and producing spores. In this study, the expression levels of four genes from myeloblastosis (MYB) Transcription factor family under compatible (CYR31) and incompatible (CYR23) strains of stripe rust were tested. The results showed TaMYB 1 transcript levels with CYR31 were induced at $12 \mathrm{hpi}$ and 48 hpi compared with the control which were about 1.5 -fold and 3.8-fold, respectively. While, the transcript levels with CYR23 were reduced with all incubated time, except 12 hpi and 48 hpi (about 2.3fold - 1.7-fold, respectively). In addition, the transcript levels were significantly reduced at $72 \mathrm{hpi}$ with both strains. Moreover, the same results were observed with TaMYB7 under the same conditions. The expression levels were significantly induced at $12 \mathrm{hpi}$ and $48 \mathrm{hpi}$, which were about 1.78-fold and 4-fold, respectively. But, at $24 \mathrm{hpi}$, the expression pattern of TaMYB7 was induced with CYR23. TaMYB2 transcript levels were reduced at all time points with both strains, except 12 hpi with CYR23. Furthermore, the TaMYB30 transcript level was induced (3.4-fold) at $12 \mathrm{hpi}$ with CYR23 compared with control. On another hand, after $12 \mathrm{hpi}$, the expression levels of TaMYB30 were reduced. Altogether, it can be concluded that TaMYB1, TaMYB2, TaMYB7 and TaMYB30 may be played roles during the interaction between wheat and stripe rust pathogen in

The $1^{\text {st }}$ Conference of Plant Protection Science Applications for Sustainable Development of Desert Areas "Effect of Climate Change on Plant Pests and Biodiversity in Desert Environment" 19-20 October, 2019, Cairo-Egypt. 
different stages.

Keywords: wheat, stripe rust, myeloblastosis, transcription factor, qRT-PCR

Domestication of agricultural crops, estimated at 2500 species globally (Meyer et al., 2012), has involved artificial selection of desirable traits that enhance yield and quality of the harvested product. While breeding for agronomic targets in high input environments has successfully increased global crop productivity (Lynch, 2007). Biotic stresses are challenges which face the plants during different growth stages. The plant depends on some of mechanisms for response and defense against different biotic stresses such as control opening/close the stomata, induce programmed cell death, induce some biochemical in the cell e.g., $\mathrm{H}_{2} \mathrm{O}_{2}, \mathrm{O}_{2}{ }^{-}$. All of these mechanisms are controlling by different genes, these genes have different roles in plant response against biotic and abiotic stresses. Among these genes, transcription factors, such as AP2/ERF, MYB, NAC, WRKY, bZIP, and bHLH, have been demonstrated to play an important regulatory role in plant response to abiotic stresses (Butt et al., 2017; Mao et al., 2017; Tang et al., 2017; Wu et al., 2017; Sun et al., 2018 and Zhu et al., 2018).

The MYB transcription factor contains a MYB domain that is highly conserved across all eukaryotes and is located at the $\mathrm{N}$ terminus, whereas the $\mathrm{C}$ terminus is variable, acting as a transacting domain, involves in the regulation of a wide range of functions in the MYB protein (Butt et al., 2017). In addition, MYB proteins contain one, two or three imperfect repeats containing 52 amino acid residues in their MYB domain (Stracke et al., 2001 and Butt et al., 2017). Based on the number of repeats in their MYB domain, the members from MYB family are divided into four groups, R2R3-MYB, MYB1-R, 4R-MYB, and R1R2R3-MYB in Arabidopsis (Stracke et al., 2001).

Since the first plant protein containing the MYB domain, named c1encoded protein, is isolated in maize (Pazares et al., 1987), numerous MYB proteins have been identified in various plant species e.g., rice, soybean, Arabidopsis and sweet orange through genome-wide analysis method (Stracke et al., 2001; Du et al. 2012 and Liu et al., 2014). Subsequent researches showed that MYB transcription factor family plays a significant role in regulatory networks that involve in the whole process of plant growth and development. The R2R3-type MYB subfamily is divided into 22 subgroups. 
However, 36 members of the R2R3-type MYB subfamily do not belong to any of these subgroups. The R2R3-MYB genes are playing different important roles in plants. For example, AtMYB52, AtMYB54, AtMYB69 and AtMYB52 are positive regulators dedicated to cell wall thickening in fiber cells. AtMYB52, AtMYB54 and AtMYB69 are hypothesized for regulating of the lignin, xylem, and cellulose biosynthesis, and AtMYB103 is involved in cellulose biosynthesis (Dubos et al., 2010; Stracke et al., 2001 and Zhong et al., 2008). Some of genes in the R2R3-MYB subfamily regulate the cell fate and identity in Arabidopsis (Kirik et al., 2005; Lepiniec et al., 2006 and Li et al., 2009). In response to pathogens attack, AtMYB44 has been shown to exhibit stronger antioxidative activities compared with other plant genes. The reactive oxygen species (ROS) burst is most likely associated with the AtMYB44-mediated signaling induced in response to biotic stresses (Shi et al., 2011 and Baohong et al., 2012). AtMYB72 is a key regulator required in the roots during the early signaling steps of induced systemic resistance and is mediated by beneficial fungus and bacteria (Van et al., 2008 and Segarra et al., 2009). Moreover, TaMYB4 have role to plant defense response against strip rust disease (Al-Attala et al., 2014). Also, BjMYB1 is potentially involved in host defense against fungal attack (Botrytis cinerea) through activating the expression of BjCHII by binding to the Wbl-4 element in the BjC-P promoter (Gao et al., 2016). MYB2 has been reported to regulate the interplay between JA and other hormones (Atkinson and Urwin, 2012). Moreover, MYB2 have role to regulate abscisic acid (ABA) signaling (Abe et al., 2003). Lignification is a mechanism for disease resistant in plants. During defense responses, lignin or lignin-like phenolic compound accumulation was shown to occur in a variety of plant-microbe interactions (Bhuiyan et al., 2009). AtMYB30 encodes an activator of the hypersensitive cell death program through the regulation of the synthesis of very-long-chin fatty acids. Additionally, AtMYB30 positively regulates hypersensitive cell death and is involved in an amplification loop or signaling cascade that modulates salicylic acid synthesis (Vailleau et al., 2002; Raffaele et al., 2006, 2008 and Li et al., 2009). TaMYB30 was shown to improve drought stress tolerance during the germination and seedling stages. Furthermore, the overexpression of TaMYB30 alters the transcript levels of some drought stress-responsive genes and changes several physiological indices to allow plants to overcome adverse 
conditions. Additionally, TaMYB32 enhances the tolerance to salt stress in plants (Zhang et al., 2012a and b). Wheat stripe rust fungus (or yellow rust) caused by Puccinia striiformis f. sp. tritici (Pst) is one of the most common and destructive diseases of wheat worldwide. Using resistant wheat cultivars is one of the most effective ways to control of wheat stripe rust fungus. A few genes have different functions in the wheat response to biotic stress.

This study investigated the role of TaMYB1, TaMYB2, TaMYB7 and TaMYB30 under biotic stress (compatible and incompatible strains) via qRTPCR. Also, study the interaction between the proteins of these genes and the other proteins using STRING database.

\section{MATERIALS AND METHODS}

\section{Plant Materials, Inoculation, and Treatments}

Suwon 11 (Su11), which is a Chinese cultivar of wheat (Triticum aestivum L.), was used to study the expression and isolation of TaMYB1, 2, 7 and 30 in response to biotic stress. Suwon 11 has been reported to carry the $\mathrm{YrSu}$ resistance gene and is highly resistant to Pst pathotype CYR23 (incompatible) and highly susceptible to CYR31 (compatible). Suwon11 seeds, Pst pathotypes (CYR23 and CYR31) were supported from State Key Laboratory of Stress Biology for Arid Areas, Northwest A and F University (NWAFU). The wheat seedlings were maintained and inoculated with CYR23 or CYR31 under controlled conditions, based on the protocols described by Stakman (1915), Kang and Li (1984) and Liu et al. (2006) and. The control treatment was inoculated with sterile distilled water. At the one-leaf stage, the seedlings were inoculated with stripe rust fungus (CYR23 or CYR31) on the surface of the wheat leaves. After inoculation, all of the plants were directly maintained in the growth chamber for $24 \mathrm{~h}$ in the dark with $100 \%$ relative humidity and a temperature of $15^{\circ} \mathrm{C}$. Leaves were harvested at $0,12,24,48$, 72 and 120 hpi. These time points were chosen based on microscopic studies of the interactions between Suwon 11 and CYR23 or CYR31, as reported by Wang et al. (2007).

\section{RNA Extraction and Reversion to cDNA}

The RNA was extracted with Biozol ${ }^{\mathrm{TM}}$ Reagent (BioFlux, Tokyo, Japan). The quality and integrity of the total RNA were determined by running $1 \mu \mathrm{l}$ of RNA with $9 \mu \mathrm{l}$ of sterile distilled water in a formamide denaturing gel.

Egyptian J. Desert Res., 69, Special Issue, 113-129 (2019) 
Additionally, the RNA quantity was estimated using a NanoDrop ${ }^{\mathrm{TM}} 1000$ spectrophotometer (Thermo Fisher Scientific, USA). To synthesize cDNA from RNA, a Revert Aid First-strand cDNA synthesis kit from Fermentas (www.thermosscientific.com/fermentas) was used.

\section{Quantitative RT-PCR Analyses Under Biotic Stress}

Quantitative real-time PCR analysis was used to determine the expression profiles of TaMYB 1, 2, 7 and 30 in response to different treatments. For the qRT-PCR analyses, four pairs of primers were designed (Table 1) to amplify different fragments under the following conditions: $95^{\circ} \mathrm{C}$ for $20 \mathrm{~s}, 40$ cycles of $95^{\circ} \mathrm{C}$ for $10 \mathrm{~s}, 55^{\circ} \mathrm{C}$ for $20 \mathrm{~s}$ and $72^{\circ} \mathrm{C}$ for $40 \mathrm{~s}$. The total volume of the PCR reaction was $25 \mu \mathrm{l}$. A 7500 Real-Time PCR System was used to quantify the gene expression. A dissociation curve was generated for each reaction to ensure specific amplification. The threshold values (CT) were generated from the ABI PRISM 7500 software (Applied Biosystems, Foster City, CA, USA). The relative expression of TaMYBs were quantified using the comparative $2^{-\triangle \Delta C T}$ method (Livak and Schmittgen, 2001). The wheat elongation factor (GenBank accession number: Q03033) was used as the internal reference for the qRT-PCR analyses. Three independent replicates were used for each time point and control.

Table (1). Oligonucleotide primers used in the study.

\begin{tabular}{ll}
\hline Gene name & Primer sequence \\
\hline TaMYB1 & F5' AGAGCACGGGTTCCACCACGACA 3' \\
& R5' GTTTCAGAGCAGGCCGAAGAATAAACAGAC 3' \\
\hline TaMYB2 & F5' GCAGGAGGAGGACCACATC 3' \\
& R5' ATCCGAACTGGCCGTACA 3' \\
\hline TaMYB7 & F5' CGAGGGCAAGGTCAAGATGA 3' \\
& R5' GACAGCGTCTCCGACCAGAA 3' \\
\hline TaMYB30 & F5' GCTTCGTGCTCAGATTGC 3' \\
& R5' GGTTGCCGAGAATCCTGT 3' \\
\hline
\end{tabular}

\section{Structural and Functional Analysis of TaMYBs Gene}

The tool NetPhos 2.0 was used for the identification of major phosphorylation site. Protein-protein interaction study was performed using STRING database. 


\section{Data Analysis}

SPSS software was used to calculate the standard deviations and to perform Tukey's test for the statistical analyses.

\section{RESULTS}

\section{Cloning and Phylogenetic Sequence Analyses of cDNA of TaMYBs Genes cDNA}

The sequences of TaMYB 1, 2, 7 and 30 were download from NCBI database and the qRT-PCR primers were designed according to these sequences. All information about these genes such as open read farms (ORF), total number of amino acids were mentioned in table (2).

Table (2). Information of TaMYBs gene.

\begin{tabular}{lccccc}
\hline Gene name & $\begin{array}{c}\text { ORF }^{*} \text { total } \\
\text { length (bp) }\end{array}$ & Amino acid & $\begin{array}{c}\text { Isoelectric } \\
\text { point }\end{array}$ & $\begin{array}{c}\text { Molecular } \\
\text { weight (Da) }\end{array}$ & $\begin{array}{c}\text { Accession no. in } \\
\text { NCBI website }\end{array}$ \\
\hline TaMYB1 & 897 & $299 \mathrm{aa}$ & 8.50 & 31914 & $\mathrm{DQ} 353858$ \\
TaMYB2 & 882 & $294 \mathrm{aa}$ & 5.74 & 31873 & $\mathrm{AB} 252145$ \\
TaMYB7 & 840 & $280 \mathrm{aa}$ & 6.49 & 30888 & $\mathrm{AB} 252147$ \\
TaMYB30 & 2199 & $733 \mathrm{aa}$ & 4.75 & 79145 & JF951913 \\
\hline
\end{tabular}

*ORF; Open Reading Frame.

${ }^{* *} \mathrm{Da}$; Daltons (measuring unit of molecular weight).

\section{TaMYBs Transcriptional Responses to the Fungal Pathogen (Puccinia} striiformis f. sp. tritici)

The transcript abundance of TaMYB1, 2, 7 and 30 in the inoculated leaves were evaluated using qRT-PCR method. With TaMYB1, the transcript level in the inoculated plant with CYR23 (incompatible) showed direct upregulation at $12 \mathrm{hpi}$ and $48 \mathrm{hpi}$ with infected leaves which were about 2.3fold and 1.7-fold, respectively. Also, at 48 hpi with CYP31, the expression pattern was up-regulated to 3.9-fold compared with control and incompatible race. The transcript levels at $24 \mathrm{hpi}$ and $48 \mathrm{hpi}$ were down-regulated with both strains compared with control. In addition, the expression patterns of TaMYB2 were investigated under the same condition. The results showed that the transcript levels of TaMYB2 were downregulated in all time points with compatible and incompatible stains except at 12 hpi with CYR23. Moreover, under the interaction with compatible race (CYR31), the expression patterns 
of TaMYB7 were induced at 12 hpi and 48 hpi (1.7-fold and 3.9-fold, respectively). On other hand, at $24 \mathrm{hpi}$ and $48 \mathrm{hpi}$, the transcript levels of TaMYB7 were reduced compared with control. But, at 24 hpi, the expression pattern of TaMYB7 was induced with CYR23. With TaMYB30, at 12 hpi, the transcript pattern of TaMYB30 was upregulated compared with all-time points. These results demonstrate that TaMYB1, 7 and 30 may have difference roles in the response of wheat during Puccinia striiformis f. sp. tritici infection with compatible race (Fig. 1).
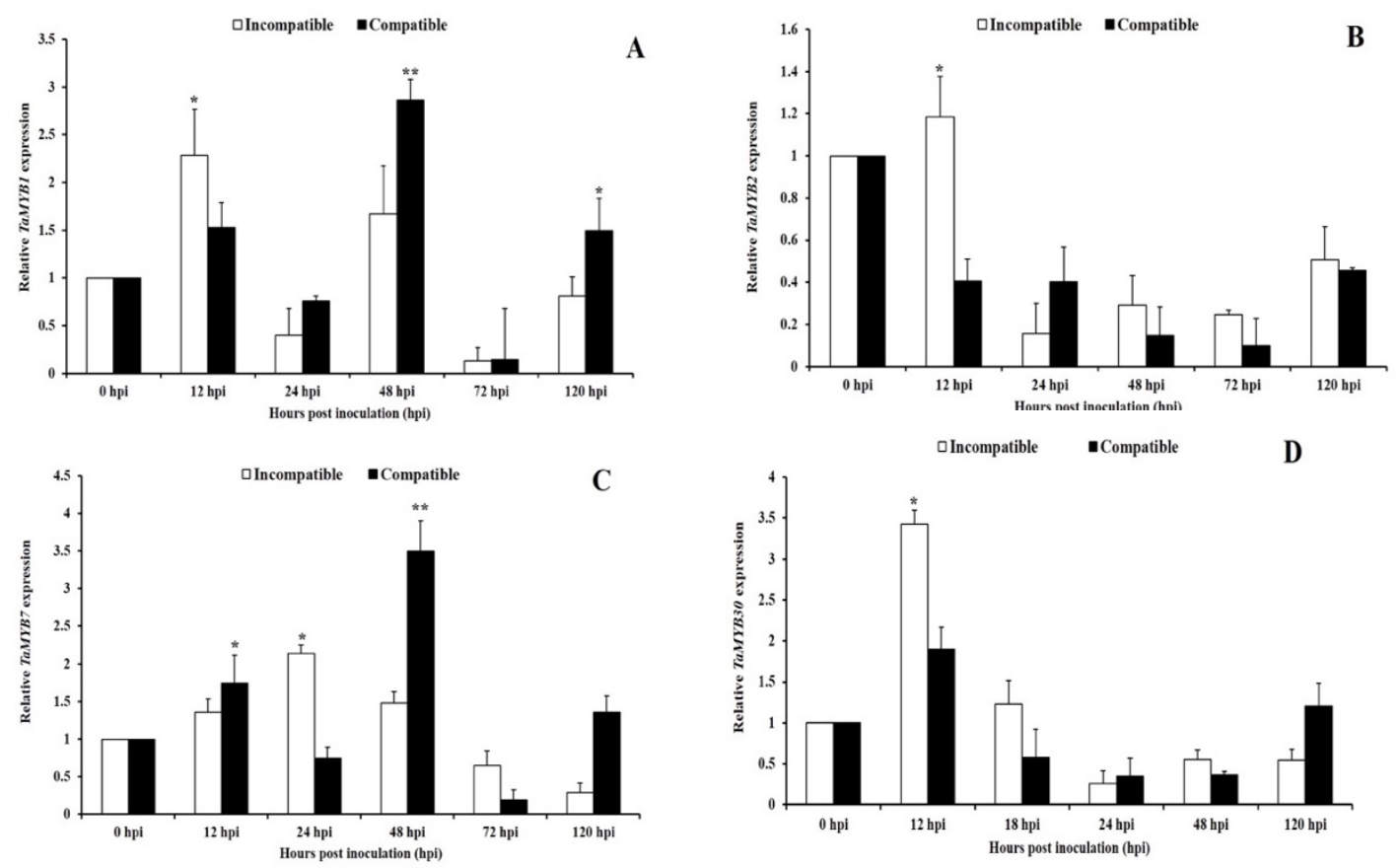

The relative gene expression was quantified using the comparative threshold $\left(2^{-\Delta \Delta \mathrm{CT}}\right)$ method. The mean and standard deviation were calculated using data from three independent biological replicates. *significantly and **high significantly.

Fig. (1). The expression pattern of TaMYB genes in wheat leaves inoculated with CYR23 (incompatible) and CYR31 (compatible). The samples were collected at 0, 12, 24, 36, 48 and 120 hpi. A, B, C and D show the expression patterns under TaMYB1, TaMYB2, TaMYB7 and TaMYB30. 


\section{Protein-Protein Interaction of TaMYB1, TaMYB2, TaMYB7 and}

\section{TaMYB30}

Protein-Protein interaction of TaMYBs network generated by the STRING database based on spring model is shown in table (3) and fig. (2). The averages local clustering coefficient of TaMYB1, TaMYB2, TaMYB7 and TaMYB30 were $0.558,0.909,0.429$ and 0.558 , respectively.

Table (3). The analysis of network stats of TaMYB 1, 2, 7 and 30 proteins.

\begin{tabular}{lccccc}
\hline Gene name & $\begin{array}{c}\text { No. of } \\
\text { nodes }\end{array}$ & $\begin{array}{c}\text { No. of } \\
\text { edges }\end{array}$ & $\begin{array}{c}\text { Average } \\
\text { node degree }\end{array}$ & $\begin{array}{c}\text { Average local } \\
\text { clustering } \\
\text { coefficient }\end{array}$ & $\begin{array}{c}\text { Ppi enrichment } \\
\text { p-value }\end{array}$ \\
\hline TaMYB1 & 11 & 26 & 4.73 & 0.558 & 0.0961 \\
\hline TaMYB2 & 11 & 10 & 1.82 & 0.909 & 0.9880 \\
\hline TaMYB7 & 11 & 31 & 5.64 & 0.429 & 0.0147 \\
\hline TaMYB30 & 11 & 26 & 4.73 & 0.558 & 0.0943 \\
\hline
\end{tabular}
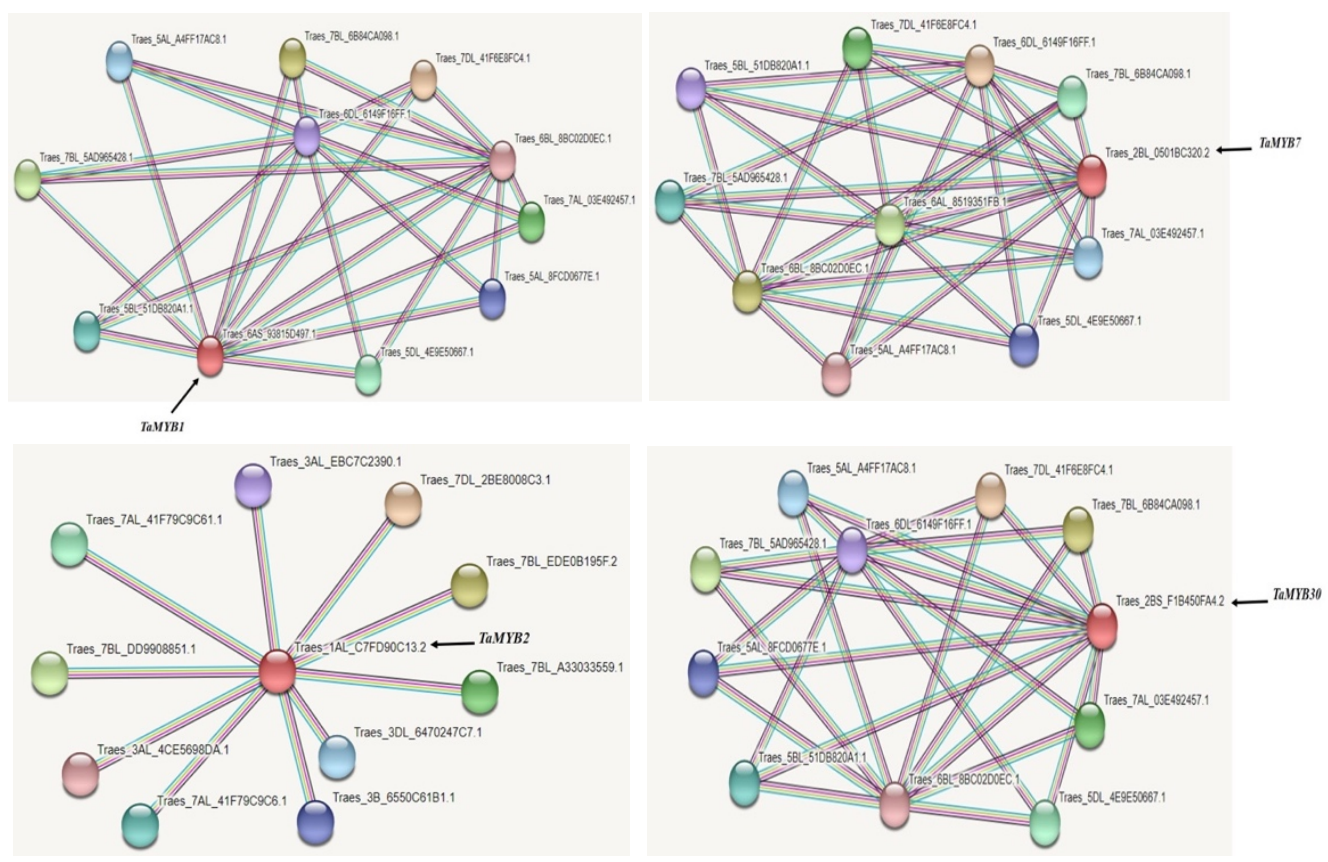

Fig. (2). Protein-protein interaction network (TaMYB1, 2, 3 and 30) generated by the STRING database based on spring model.

Egyptian J. Desert Res., 69, Special Issue, 113-129 (2019) 


\section{DISCUSSION}

Stripe rust (yellow rust) is caused by Puccinia striiformis f. sp. tritici Eriks \& E. Henn. (syn. P. glumarum Eriks and Henn.) and is widely regarded as one of the most destructive diseases that affect wheat (Triticum aestivum L.) worldwide. The flexibility and adaptability of this pathogen makes it very serious and it is present on all continents, where it can cause wheat production losses of $30-100 \%$ by destroying leaf tissue, as well as reducing the crop weight and quality (Chen, 2005 and Kolmer, 2005)

For more a decade ago, the concept of plant innate immunity as a twolayer defense system comprising broad-spectrum pattern triggered immunity (PTI) and isolate-specific effector-triggered immunity (ETI) was first proposed. PTI is thought to be controlled by conserved cell-surface patternrecognition receptors (PRRs), such as receptor-like proteins and receptor-like kinases (RLKs) including wall-associated kinase genes (WAKs), after perception of conserved pathogen associated or plant-derived damageassociated molecular patterns, such as chitin or pectic oligogalacturonide derivatives of fungal or plant cell walls, respectively. After this first level of defense is overcome, plants may deploy ETI with highly variable, often dispensable resistance proteins (cytoplasmic NLRs or extracellular-receptorlike proteins) that detect matching avirulence (Avr) effectors, which are also highly variable. ETI frequently culminates in a hypersensitive response and is often described as faster and stronger than PTI. The above concepts are being challenged by the accumulation of new data suggesting that plant immunity is likely to be a continuous surveillance system that evolves to detect invading microbes. In particular, there may be no strict dichotomy between PTI and ETI, or between PRRs and resistance proteins (Postel and Kemmerling, 2009 and Dardick et al., 2012)

An R2R3-MYB protein contains two MYB domains and the majority of R2R3-MYB proteins regulate plant-specific functions including immunity against microbial pathogens (Stracke et al., 2001 and Dubos et al., 2010). For example, overexpression of the R2R3-MYB gene HbMybl from Hevea brasiliensis enhances resistance to $B$. cinereal in transgenic tobacco Nicotiana tabacum cultivar (Ambawat et al., 2013). The R2R3-MYB gene OsJaMyb in rice (O. sativa spp. japonica) is responsive to infection by the blast fungus Magnaporthe oryzae (Lee et al., 2001). The Botrytis cinerea-induced mRNA 
expression pattern of BjMYBI from Brassica juncea was similar to that of $B j C H I 1$ in the native host plant $B$. juncea. Overexpression of BjMYB1 in stable, transgenic Arabidopsis thaliana plants enhanced host plant resistance to $B$. cinerea. These results suggest that BjMYB1 might be involved in plant defense against fungal infection by interacting with the Wbl-4 element and regulating the expression of BjCHII for host plant defense (Gao et al., 2016). Moreover, the expression levels of TaMYB2 were reduced with all-time points in compatible and incompatible strains Previous studies have been reported that Some MYB genes are expressed in response to GA treatment in Petunia petals. Another plant hormone, Abscisic acid (ABA), induces expression of AtMYB2 in Arabidopsis, a MYB gene that is also induced in response to dehydration or salt stress (Shinozaki et al., 1992). AtMYB2, AtMYB74 and AtMYB102 were up-regulated by drought stress (Urao et al., 1993; Abe et al., 2003 and Denekamp and Smeekens, 2003). AtMYB2 was induced by dehydration and salt stress but not by cold and heat stress and thus $A t M Y B 2$ is responsive to dehydration at the transcriptional level. Moreover, OsMYB2, was involved in salt, cold, and dehydration tolerance in rice (Yang et al., 2012). So, it can be concluded that TaMYB2 have more function in plant response under abiotic stress.

Based on the obtained results, the expression patterns of TaMYB7 were induced at $12 \mathrm{hpi}$ and $48 \mathrm{hpi}$ with compatible race of Pst. While, transcript level was induced at 24 hpi with incompatible race of Pst. The previous studies reported that carbohydrates are important components in the adjustment process, and many studies have shown that when plants were stressed by drought, low temperature, high temperature and certain biological stresses, the plant tissues will accumulate substantial levels of fructose and sorbitol to maintain cell turgor (Couee et al., 2006 and Lee et al., 2016). MYB10, MYB4 and MYB7 have upregulated with accumulated of carbohydrates in stressed plants. The previous study suggested that carbohydrates, which are components of osmotic regulation during pathogen infection, may contribute to the accumulation of flavonoids as defense factors against infection and disease expansion because of their antioxidant properties (Das et al., 2012; Di et al., 2017 and Zhu et al. 2017). So, the results suggested TaMYB7 may be plays role under biotic stresses. With all studied TaMYBs, the expression levels were induced at $120 \mathrm{hpi}$, it could be related to help the

Egyptian J. Desert Res., 69, Special Issue, 113-129 (2019) 
plant cell to regain balance after response to stress.

Activation of immunity is achieved by multiple transcriptional regulators that reprogram cell transcription to favour defense over routine cellular requirements (Moore et al., 2011). The arsenal of transcriptional regulators consists not only of DNA-binding transcription factors (TFs), but also of proteins that interact with and regulate these TFs. MYB30, an Arabidopsis R2R3-type MYB TF, as a positive regulator of plant defense and HR responses. MYB30 activates genes related to the lipid biosynthesis pathway that leads to the production of very-long-chain fatty acids (VLCFAs) (Vailleau et al., 2002 and Raffaele et al., 2008). Previous study has been reported that MYB30 is targeted by the Xanthomonas campestris pv. Campestris (Xcc) effector XopD, suppressing MYB30 transcriptional activity and thereby plant resistance (Canonne et al., 2011). Here, the results showed that the transcript levels were induced at $12 \mathrm{hpi}$ with incompatible race of Pst and then the expression patterns were reduced with all of time points. Altogether, it can be concluded that TaMYB1, TaMYB2, TaMYB7 and TaMYB30 may play important roles plant response against strip rust. Additionally, these genes may have different roles during wheat defense stages.

\section{CONCLUSIONS}

Form this study, It can be concluded that TaMYB1, TaMYB2, TaMYB7 and TaMYB30 may play difference roles during wheat response against strip rust pathogen. Moreover, these genes have responsibility to control several genes which are have roles in wheat defense response.

\section{REFERENCES}

Abe, H., T. Urao, T. Ito, M Seki., K. Shinozaki and K. Yamaguchi Shinozaki (2003). Arabidopsis AtMYC2 (bHLH) and AtMYB2 (MYB) function as transcriptional activators in abscisic acid signaling. The Plant Cell, 15: 63-78.

Al-Attala, M.N., X. Wang, M.A. Abou-Attia, X. Duan and Z. Kang (2014). A novel TaMYB4 transcription factor involved in the defense response against Puccinia striiformis f. sp. tritici and abiotic stresses. Plant Molecular Biology, 84 (4-5): 589-603.

Ambawat, S., P. Sharma, N.R. Yadav and R.C. Yadav (2013). MYB 
transcription factor genes as regulators for plant responses: an overview. Physiology and Molecular Biology of Plants, 19 (3): $307-$ 321.

Atkinson, N.J. and P.E. Urwin (2012). The interaction of plant biotic and abiotic stresses: from genes to the field. Journal of Experimental Botany, 63 (10): 3523-3543.

Baohong Z., J. Zhenhua, T. Shuangmei, W. Xiaomeng, G. Zhenhua, L. Beibei and D. Hansong (2012) AtMYB44 positively modulates disease resistance to Pseudomonas syringae through the salicylic acid signaling pathway in Arabidopsis. Functional Plant Biology, 40: 304 313

Bhuiyan, N.H., G. Selvaraj, Y. Wei and J. King (2009). Role of lignification in plant defense. Plant Signaling and Behavior, 4 (2): 158-159.

Butt, H.I., Z. Yang, G. Qian, E. Chen, X. Wang, Z. Ge, X. Zhang and F. Li (2017). GaMYB85, an R2R3 MYB gene, in transgenic Arabidopsis plays an important role in drought tolerance. BMC Plant Biology, 17: 142.

Canonne, J., D. Marino, A. Jauneau, C. Pouzet, C. Brière, D. Roby and S. Rivas (2011). The Xanthomonas Type III effector XopD targets the Arabidopsis transcription factor MYB30 to suppress plant defense. The Plant Cell, 23 (9): 3498-3511.

Chen, X.M. (2005). Epidemiology and control of stripe rust on wheat [Puccinia striiformis f. sp. tritici] on wheat. Canadian Journal of Plant Pathology, 27: 314-337.

Couee I., C. Sulmon, G. Gouesbet and A. El Amrani (2006). Involvement of soluble sugars in reactive oxygen species balance and responses to oxidative stress in plants. Journal of Experimental Botany, 57: 449459.

Dardick, C., B. Schwessinger and P. Ronald (2012). Non-arginine-aspartate (non-RD) kinases are associated with innate immune receptors that recognize conserved microbial signatures. Current Opinion in Plant Biology, 15: 358-366.

Das, P.K., D.H. Shin, S.B Choi. and Y.I. Park (2012). Sugar-hormone crosstalk in anthocyanin biosynthesis. Molecules and Cells, 34: 501-507.

Denekamp, M. and S.C. Smeekens (2003). Integration of wounding and 
osmotic stress signals determines the expression of the AtMYB102 transcription factor gene. Plant Physiology, 132: 1415-1423.

Di, X.T., J. Gomila and F.L.W. Takken (2017). Involvement of salicylic acid, ethylene and jasmonic acid signalling pathways in the susceptibility of tomato to Fusarium oxysporum. Molecular Plant Pathology, 18 (7): 1024-1035.

Du, H., S.S. Yang, Z. Liang, B.R. Feng, L. Liu, Y. B. Huang and Y.X. Tang (2012). Genome-wide analysis of the MYB transcription factor superfamily in soybean. BMC Plant Biology, 12: 106.

Dubos, C., R. Stracke, E. Grotewold, B. Weisshaar, C. Martin and L. Lepiniec (2010). MYB transcription factors in Arabidopsis. Trends Plant Science, 15: 573-581.

Gao, Y., S. Jia, C. Wang, F. Wang, F. Wang and K. Zhao (2016). BjMYB1, a transcription factor implicated in plant defense through activating BjCHI1 chitinase expression by binding to a W-box-like element. Journal of Experimental Botany, 67 (15): 4647-4658.

Kang, Z.S. and Z.Q. Li (1984). Discovery of a normal T type new pathogenic strain to lovrin10. Acta Cllegii Septentrionali Occidentali Agric., 4: $18-28$.

Kirik, V., M.M. Lee, K. Wester, U. Herrmann, Z. Zheng, D. Oppenheimer, J. Schiefelbein and M. Hulskamp (2005). Functional diversification of MYB23 and GL1 genes in trichome morphogenesis and initiation. Development, 132: 1477-1485.

Kolmer, J.A. (2005). Tracking wheat rust on a continental scale. Curr. Opin. Plant Biol., 8: 441-449.

Lee, M.W., M. Qi and Y. Yang (2001). A novel jasmonic acid-inducible rice myb gene associates with fungal infection and host cell death. Molecular Plant-Microbe Interactions, 14: 527-535.

Lee, D.K., S. Ahn, H.Y. Cho, H.Y. Yun, J.H. Park and S.W. Kwon (2016). Metabolic response induced by parasitic plant-fungus interactions hinder amino sugar and nucleotide sugar metabolism in the host. Scientific Reports, 6: 37434.

Lepiniec, L., I. Debeaujon, J. Routaboul, A. Baudry, L. Pourcel, N. Nesi and M. Caboche (2006). Genetics and biochemistry of seed flavonoids. Annual Review of Plant Biology, 57: 405-430. 
Li, L., X.F. Yu, M.G. Thompson, S. Yoshida, T. Asami, J. Chory and Y.H. Yin (2009). Arabidopsis MYB30 is a direst target of BES1 and cooperates with BED1 to regulate brassinosteroid-induced gene expression. Plant Journal, 58: 275-286.

Liu, H.M., T.G. Liu, S.C. Xu, D.Q. Liu and W.Q. Chen (2006). Inheritance of yellow rust resistance in an elite wheat germplasm Xingzi 9104. Acta Agron. Ainica, 32: 1742-1745.

Liu, C., X. Wang, Y. Xu, X. Deng and Q. Xu (2014). Genome-wide analysis of the R2R3-MYB transcription factor gene family in sweet orange (Citrus sinensis). Molecular Biology Reports, 41: 6769-6785.

Livak, K.J. and T.D. Schmittgen (2001) Analysis of relative gene expression data using real-time quantitative PCR and the $2^{-\triangle \Delta C T}$ method. Methodology, 25: 402-408.

Lynch, J.P. (2007). Roots of the second green revolution. Australian Journal of Botany, 55: 493-512.

Mao, K., Q. Dong, C. Li, C. Liu and F. Ma (2017). Genome wide identification and characterization of apple bHLH transcription factors and expression analysis in response to drought and salt stress. Frontiers in Plant Science, 8: 480.

Meyer, R.S., A.E. DuVal and H.R. Jensen (2012). Patterns and processes in crop domestication: an historical review and quantitative analysis of 203 global food crops. New Phytologist, 196: 29-48.

Moore, J.W., G.J. Loake and S.H. Spoel (2011). Transcription dynamics in plant immunity. Plant Cell, 23: 2809-2820.

Pazares, J., D. Ghosal, U. Wienand, P.A. Peterson and H. Saedler (1987). The regulatory $\mathrm{c} 1$ locus of Zea mays encodes a protein with homology to myb proto-oncogene products and with structural similarities to transcriptional activators. The EMBO Journal, 6: 3553-3558.

Postel, S. and B. Kemmerling (2009). Plant systems for recognition of pathogen-associated molecular patterns. Seminars in Cell and Developmental Biology, 20: 1025-1031.

Raffaele, S., S. Rivas and D. Roby (2006). An essential role for salicylic acid in AtMYB30-mediated control of the hypersensitive cell death program in Arabidopsis. FEBS Letters, 580: 3498-3504.

Raffaele, S., F. Vailleau, A. Leger, J. Joubes, O. Mierch, C. Huard, E. Blee, S. 
Mongrand, F. Domergue and B. Roby (2008). A MYB transcription factor regulates very long chain fatty acid biosynthesis for activation of the hypersensitive cell death response in Arabidopsis. Plant Cell, 20: 752-767.

Segarra, G., S.D.E. Van, I. Trillas and C.M.J. Pieterse (2009). MYB72, a node of convergence in induced systemic resistance triggered by a fungal and a bacterial beneficial microbe. Plant Biology, 11: 90-96

Shi, H., R. Cui, B. Hu, X. Wang, S. Zhang, R. Liu and H. Dong (2011) Overexpression of transcription factor AtMYB44 facilitates Botrytis infection in Arabidopsis. Physiological and Molecular Plant Pathology, 76: 90-95

Shinozaki, K., K. Yamaguchi-Shinozaki, O.T. Urao and M Koizumi (1992). Nucleotide sequence of a gene from Arabidopsis thaliana encoding a myb homologue. Plant Molecular Biology, 19: 493-499.

Stakman, E.C. (1915). Relation between Puccinia graminis and plants highly resistant to its attack. Journal of Agricultural Research, 4: 193-201.

Stracke, R., M. Werber and B. Weisshaar (2001). The R2R3-MYB gene family in Arabidopsis thaliana. Current Opinion in Plant Biology, 4: 447456.

Sun, H., M. Hu, J. Li, L. Chen, M. Li, S. Zhang, X. Zhang and X. Yang (2018). Comprehensive analysis of NAC transcription factors uncovers their roles during fiber development and stress response in cotton. BMC Plant Biology, 18: 150.

Tang, Y., K. Liu, J. Zhang, X. Li, K. Xu, Y. Zhang, J. Qi, D. Yu, J. Wang and C. Li (2017). JcDREB2, a physic nut AP2/ERF gene, alters plant growth and salinity stress responses in transgenic rice. Frontiers in Plant Science, 8: 306.

Urao, T., K. Yamaguchi-Shinozaki, S. Urao and K. Shinozaki (1993). An Arabidopsis myb homolog is induced by dehydration stress and its gene product binds to the conserved MYB recognition sequence. Plant Cell, 5: 1529-1539.

Vailleau, F., X. Daniel, M. Tronchet, J.L. Montillet and C. Triantaphylides (2002). A R2R3-MYB gene, AtMYB30, acts as appositive regulator of the hypersensitive cell death program in plants in response to pathogen attack. PNAS, 99: 10179-10184. 
Van, S.D.E, B.W. Verhagen, R.V. Doorn, D. Bakker, M.G. Verlaan, M.J. Pel, R.G. Joosten, M.C. Proveniers, L.C. Loon, J. Ton and C.M. Pieterse (2008). MYB72 is required in early signaling steps of rhizobacteriainduced systemic resistance in Arabidopsis. Plant Physiology, 146: 1293-1304.

Wang, C., L. Huang, H. Buchenauer, Q. Han, H. Zhang and Z. Kang (2007). Histochemical studies on the accumulation of reactive oxygen species $\left(\mathrm{O}_{2}-\right.$ and $\left.\mathrm{H}_{2} \mathrm{O}_{2}\right)$ in the incompatible and compatible interaction of wheat Puccinia striiformis f. sp. tritici. Physiological and Molecular Plant Pathology, 31: 230-239.

Wu, J., J. Chen, L. Wang and S. Wang (2017). Genome-wide investigation of WRKY transcription factors involved in terminal drought stress response in common bean. Frontiers in Plant Science, 8: 380.

Yang, A., X. Dai and W.H. Zhang (2012). A R2R3-type MYB gene, OsMYB2, is involved in salt, cold, and dehydration tolerance in rice. Journal of Experimental Botany, 63 (7): 2541-2556.

Zhang, L.C., G.Y. Zhao, J.Z. Jia and X.Y. Kong (2012a) Molecular characterization of 60 isolated wheat MYB genes and analysis of their expression during abiotic stress. Journal of Experimental Botany, 63: 203-214.

Zhang, L.C., G.Y. Zhao, C. Xia, J.Z. Jia, X. Liu and X.Y. Kang (2012b). A wheat R2R3-MYB gene, TaMYB30-B, improves drought stress tolerance in transgenic Arabidopsis. Journal of Experimental Botany, 63: 5873-5885.

Zhong, R.Q., C.H. Lee, J.L. Zhou, R.L. McCarthy and Z.H. Ye (2008). A battery of transcription factors involved in the regulation of secondary cell wall biosynthesis in Arabidopsis. Plant Cell, 20: 2763-2782.

Zhu, L., W. Ni, S. Liu, B. Cai, H. Xing and S. Wang (2017). Transcriptomics analysis of apple leaves in response to Alternaria alternate apple pathotype infection. Frontiers in Plant Science, 8: 22.

Zhu, M., X. Meng, J. Cai, G. Li, T. Dong, and Z. Li (2018). Basic leucine zipper transcription factor SIbZIP1 mediates salt and drought stress tolerance in tomato. BMC Plant Biology, 18: 83.

Egyptian J. Desert Res., 69, Special Issue, 113-129 (2019) 


\section{دور بعض جينات MYB في الاستجابة الدفاعية للقمح ضد مرض الصدأ الأصفر}

محمد نشأت العطلة

قسم وقاية النبات، مركز بحوث الصحر اء، المطرية، القاهرة، مصر

يعتبر القمح واحد من أهم المحاصيل الغذائية في العالم وهو الغذاء الأساسي في العديد من

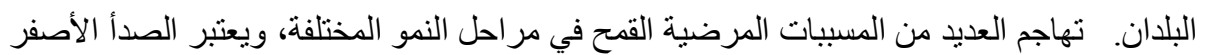

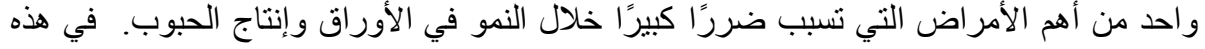

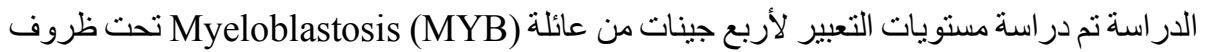
العدوى الصناعية من سلالتني؛ الأولى منو افقة (CYR31) والثانية غير متو افقة (CYR23) من الصناف

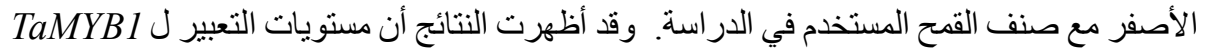

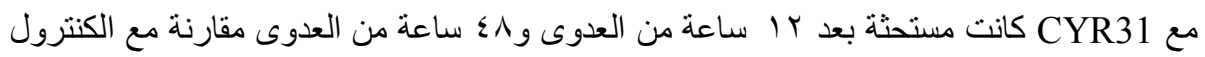

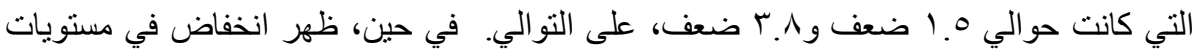

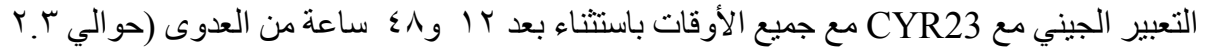

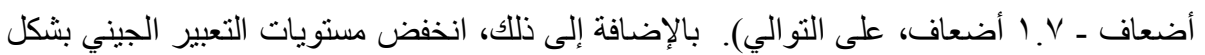

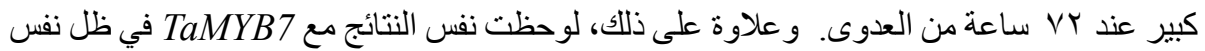

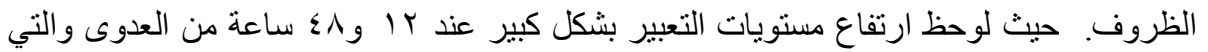

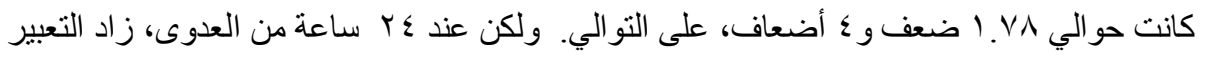

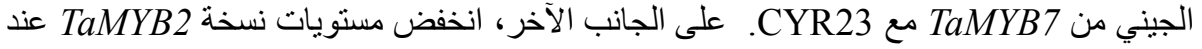

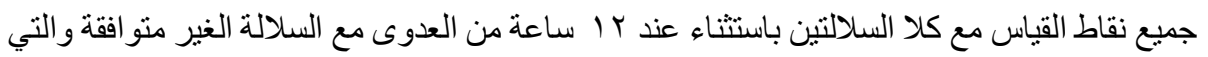

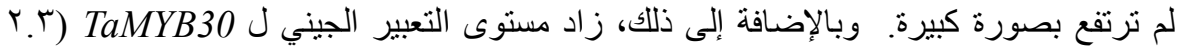

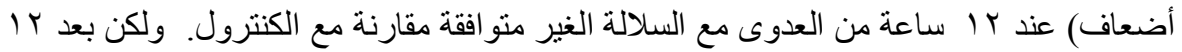

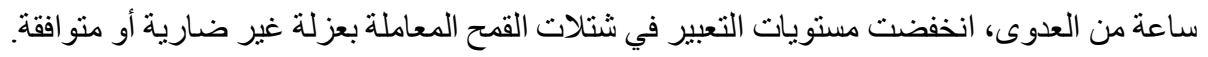

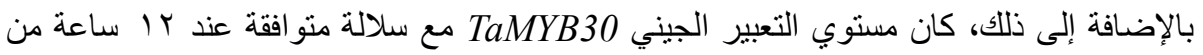

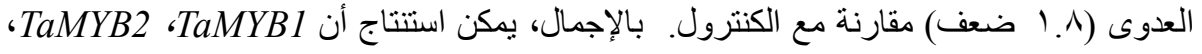

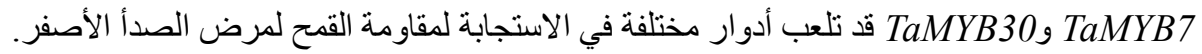

